\title{
Reform Trend and Countermeasures of Martial arts Teaching Content in Colleges and Universities
}

\author{
Zhao Xun \\ Baicheng Normal University, Baicheng, 137000, China \\ email: 63659198@qq.com
}

Keywords: Martial Arts, College Physical Education, Teaching Contents, Reform Strategy

\begin{abstract}
Martial arts has lifelong value for Martial arts practitioners, and it is also one of the important contents of physical education in modern colleges and universities. With the deepening of the reform of education and teaching system, some achievements have been made in the course teaching of martial arts major in Chinese universities and colleges, and some teaching experiences have also been summarized. However, on the whole, there are still some problems and deficiencies in martial arts teaching content in colleges and universities. This paper analyzes this problem, and on the basis of this, discusses the personal viewpoint and understanding on how to innovate and improve martial arts teaching for reference.
\end{abstract}

\section{Introduction}

At present, most colleges and universities in China have included martial arts in physical education, that is, the teaching hours has been stipulated, more standardized assessment methods and standards have also been formulated. It is worth mentioning that some colleges and universities have also set up martial arts teams, who have achieved good results in all kinds of martial arts competitions in China or in the provinces. On the one hand, that have promoted the development of the national fitness cause in China. On the other hand, that also promotes the promotion of Chinese martial arts culture.

\section{Problems Analysis on the Content of Martial Arts Teaching in Colleges and Universities in China}

Teaching content is the key of martial arts education and teaching in colleges and universities at present, and it is also the main goal of martial arts teaching. According to the Provisions of the Outline of the Education Plan, the teaching contents of martial arts courses in colleges and universities are independent and selective at present[1]. In order to further analyze and study this problem, the author takes 10 colleges and universities in China as the object of questionnaire, the statistical data are as follows:

Table.1 Contents of martial arts teaching in 10 investigated universities

\begin{tabular}{|c|c|c|c|}
\hline $\begin{array}{c}\text { Contents of martial } \\
\text { arts teaching }\end{array}$ & Number of schools & Percentage(\%) & $\begin{array}{c}\text { Marshalling } \\
\text { sequence }\end{array}$ \\
\hline 24 simplified Taiji & 9 & 90 & 1 \\
\hline Primary sword & 6 & 60 & 2 \\
\hline $\begin{array}{c}\text { Primary long } \\
\text { boxing }\end{array}$ & 4 & 40 & 3 \\
\hline free combat & 2 & 20 & 5 \\
\hline $\begin{array}{c}\text { Health care and } \\
\text { health care skill }\end{array}$ & 1 & 10 & 5 \\
\hline other content & 1 & 10 & 5 \\
\hline
\end{tabular}

Through the investigation and summary of the martial arts teaching contents in these 10 universities in China, we can see that the most important teaching contents are the simplified 
Taijiquan and Taiji sword, and few schools are interested in the courses of Sanda and health care. It is worth mentioning that the traditional Chinese boxing, capture and equipment and other sports events has been opened in every universities, which shows that the content of martial arts teaching is very simple. For Taijiquan and Taiji Sword, it is easier to learn and train, and the amount of exercise is very small, which is more suitable for girls. In contrast, boys prefer more confrontational sports such as Sanda, but colleges and universities worry that offering martial arts courses such as Sanda will bring security risks. For these martial arts teaching contents, the students are not motivated and initiative, and the school forces students to study, so that the students are as if they are to be decocted. In addition, many students point out that the martial arts teacher overstress the repeated training of martial arts routine in class, and has no systematic study on the theory of martial arts. Through the questionnaire survey, it is found that the students hope to incorporate the meaning of attack and defense contained in one move into the process of martial arts routine teaching in colleges and universities, and adopt the cooperative mode of actual combat exercises in the martial arts classroom teaching process, interspersed with the philosophy of national philosophy and the thought of cultural health preservation contained in the routine of martial arts, colleges and universities are strongly requested to incorporate the training of loose hands and traditional skills into the curriculum[2]. Through a survey of students satisfaction with the content of martial arts teaching, the results are shown in the figure below.
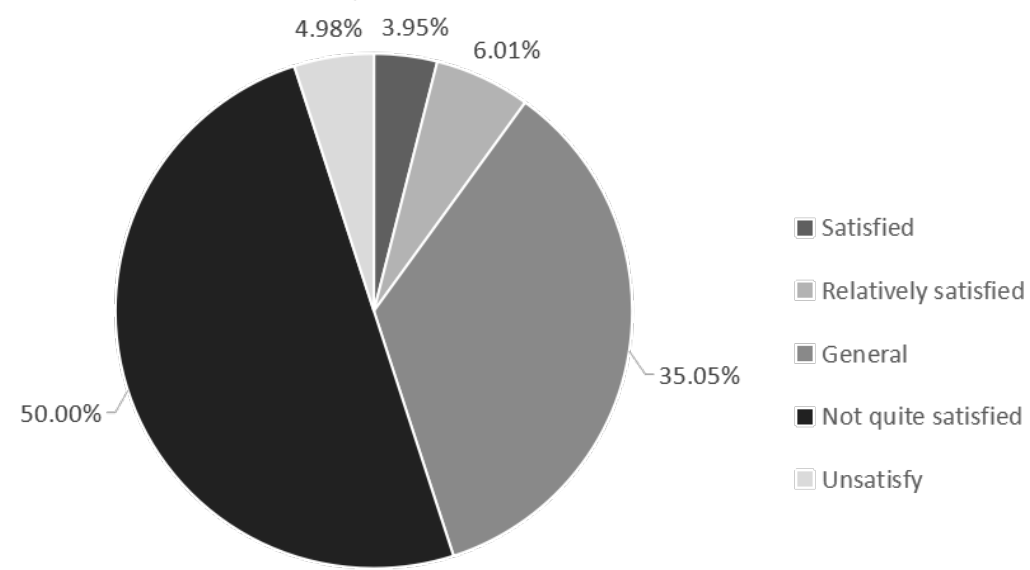

Fig.1. Students satisfaction with the content of martial arts teaching in colleges and universities $(\mathrm{N}=582)$

As shown in figure 1, at this stage, the satisfaction of ordinary students on martial arts teaching content is not high, the proportion of satisfied and more satisfied students is only 9.96, half of the students express clearly that they are not satisfied with the martial arts teaching content at this stage. About $4.98 \%$ of the students surveyed were not satisfied with the current content of martial arts teaching. At the same time, most of the students are not satisfied with the content of martial arts course at the present stage, and more teach martial arts routine, the movement is very complex, that is difficult to grasp the martial arts movement essentials accurately. At present, in the process of martial arts teaching in colleges and universities, it pays more attention to technical action, neglects the connotation and essence of martial arts seriously, and the content of martial arts culture is less, so the teaching effect of martial arts technique and defensive skill is not ideal[3]. Overall, the main issues are the followings:

The Syllabus is out of Date and the Content of Martial Arts Teaching Materials Lacks Characteristics. In practice, although most colleges and universities in China have formulated martial arts teaching program, the formulation time is from 2002 to 2008. However, the outline ten years ago is no longer adapted to the requirements of modern development and does not accord with the psychological demands and characteristics of college students. Through the questionnaire survey, it is found that the martial arts teaching in colleges and universities does not specify which teaching materials to refer to, and the common concept is "reference textbooks", and the teaching materials and contents of martial arts teaching are freely decided by the teachers. In this case, different teachers teach different contents, content versions vary greatly, students feel confused, teaching is 
difficult to see results[4].

The Content is rather Monotonous and the Choice is Poor. First, the theoretical content is scarce. Chinese martial arts always regards both form and spirit as its tenet, and emphasizes the unity of internal and external and the combination of virtue and art, in which the combination of form and spirit refers to the high unity of form and ecology. For martial arts practitioners, we should be able to cut off the potential and gas link, shape cut and intend to connect. For the unity of internal and external, it mainly refers to the unity of man and nature, and also requires the unity of internal and external, subjective and objective. The investigation shows that at present, except for the students majoring in martial arts, other majors in our country only offer practical courses, and there are no special courses of martial arts theory, and even martial arts culture has never been involved. In other words, in the process of martial arts teaching in modern colleges and universities, martial arts is only regarded as a way and method to exercise the body, it is only a simple imitation of the movement, and there is no deep explanation of the connotation of martial arts. However, in the process of teaching and learning of martial arts, teachers and students expect to reform the teaching content, and to include the content and value of martial arts theory as well as martial arts culture, covering characters and stories. Second, martial arts project pays too much attention to competition. From the point of view of the investigated universities, martial arts teaching is more around the basic competitive routine, with Taijiquan, Changquan and primary sword as the focus, some colleges and universities also set up a small amount of duel and boxing and so on[5]. Martial arts teaching content is seriously divorced from teaching materials, there is often a free preparation of martial arts teaching content phenomenon, students do not know the connotation of martial arts attack and defense, which is contrary to the original intention of martial arts teaching. Many teachers and students expect to include traditional boxing, grappling and health-preserving skills in martial arts teaching.

Teaching Arrangements Remain to be Studied. Martial arts are diverse, and the routines are complex, with some music or the qualities of the practitioner, such as flexibility, endurance, and exploding. If keeping doing repetitive exercises, students will feel very dull and boring, so that the students satisfaction with the arrangement of martial arts teaching will be reduced, and students will not want to learn martial arts. At the same time, there is a phenomenon that female martial arts teaching satisfaction is higher than boys, some colleges and universities due to subject setup or enrollment and other reasons, the ratio of men and women is seriously out of balance; however, martial arts teaching content in colleges and universities will be combined with the development trend, so it will ignore the needs of small groups. It is worth mentioning that the gender of students also affects their requirements for martial arts teaching content[6]. As an independent individual, there are great differences in students interests and hobbies, and there are great differences in cognition among students of different genders about the reform trend of martial arts teaching content, such as male students prefer strength and speed-type martial arts items, Nanquan, Changquan and other martial arts are the most popular; girls prefer coordinated, flexible projects, with Taijiquan, martial arts fans and other martial arts projects are more popular.

\section{Reform Path of Martial Arts Teaching Content in Colleges and Universities}

Based on the investigation and study of the problems existing in the martial arts technology content in colleges and universities at the present stage, the author thinks that the martial arts teaching in colleges and universities is facing new opportunities for development at the present stage, and must be reformed and innovated on the basis of reality.

Streamline Martial Arts Routine Hours and Stimulate Students Enthusiasm and Enthusiasm for Participation. For the content of martial arts teaching, the martial arts routine should be short and concise to highlight the essence of sports. It can be seen in practice that the general martial arts routine, especially the athletics discussion, contains four or more paragraphs, so that the students are tired and unable to attract their attention, and of course, there is no good feedback on the effect of classroom teaching. In the course of reform of martial arts teaching content, we should choose more martial arts items which students prefer, and should also flexibly 
intercept some of the martial arts activities, even adapt the movements according to the needs, and innovate the short routine. By creating teaching situations, students are willing to understand and master martial arts routines at a deeper level so as to enhance their enthusiasm and enthusiasm for participation[7].

The Contents of Teaching are Diversified and Meet the Needs of Different Students. The development of martial arts teaching content in a diversified direction can be said to be the psychological appeal of every teacher and student. In practice, colleges and universities should base themselves on reality and provide students with more choices in martial arts content. Students interest in martial arts projects will naturally be very high when they choose which items they like and in this process teachers should not feel slacked by repeated teaching of martial arts. In the course of public physical education, we should combine the characteristics and demands of the students to carry out diversified teaching, not limited to the established martial arts and competitive routines. It is suggested that some folk martial arts and traditional routines be added to them, and martial arts teaching contents should be set up scientifically and rationally to meet the demands of different students to the maximum combined with students physical and psychological conditions.

Inherit the Culture of Martial Arts and Strengthen the Education of Martial Morality. Health skills have fitness and health two elements, after learning, martial arts persons will benefit all their lives. The arrangement of teaching contents should follow the law of nature and martial arts movements stress efficacy. At the same time, we should carry out martial arts education to broaden students horizons and inherit Chinese martial arts culture. The contents of martial arts include many subjects, such as philosophy, aesthetics and health preservation, which are closely related to traditional Chinese medicine and art of war. In the course of reform of martial arts teaching content in colleges and universities, it is possible to broaden students horizons and promote their martial arts literacy by effectively integrating martial arts education. Martial arts moral education is also conducive to the inheritance and development of martial arts content. The forefathers used to sum up martial arts as "Hezong", "Dinggong", "Anmin" and "Jinbao" and so on. With the development of history, the connotation of martial arts is more abundant. Although there are obvious differences in content level, it does not fundamentally change its essential connotation, that is to say, righteousness, propriety, respect, trust and courage. Under the influence of traditional thought, although the education of military morality may be influenced to some extent, it is not without merit. In practice, we should take the essence, discard the dross, inherit the essence of martial arts and carry it forward. In the process of martial arts teaching in colleges and universities, we should mainly carry forward the ideas of emphasizing faith, courtesy, justice, patriotism, and so on. The combination of martial arts and society will guide students to set up the spirit of excellence. Martial arts teachers in colleges and universities should closely link their skills with the teaching of martial arts in order to cultivate modern people with positive energy and noble morality. At the same time, this is the necessity of carrying out the education of martial arts.

Learn and Practice Offensive and Defensive Skills and Inherit the Spirit of Chinese Martial Arts. In the teaching process of martial arts course in colleges and universities, especially when choosing the teaching content, we should pay attention to practicality and actual combat, which is helpful to arouse the students enthusiasm for participation. If it is only the embroidered legs, I am afraid that the enthusiasm of the students will last for a short time. The investigation found that the actual combat martial arts skills are popular among the students, and the students participation and enthusiasm are higher. Therefore, in the teaching process of martial arts in colleges and universities, we should highlight the martial arts skills and actual combat, so as to return to the true nature of martial arts. By learning and practicing attack and defense martial arts, not only can we effectively train the students will quality and cultivate their spirit of perseverance and unyielding, but more importantly, we can effectively inherit the Chinese martial arts culture and carry forward the national spirit[8].

Optimize the Course Content and Enhance the Novelty of Martial Arts Teaching Content. For each university, there are great differences in its characteristics, in addition, there are significant stratification of students gender, personality and hobbies. For example, there are more male 
engineering students in some schools and more female students in normal schools .Based on this, in the process of innovation and arrangement of martial arts teaching content, different programs are adopted by colleges and universities. In particular, reasonable arrangements should be made according to students preferences, teachers strength and regional characteristics, etc, and special attention should be paid to the demands of small groups. For boys classes, martial arts teaching should be based on martial arts courses with relatively strong sports intensity, and must have a certain degree of technical strength. For girls classes, simple martial arts items such as Taijiquan and women self-defense techniques are the main ones, that is in line with the female college students sentiment and self-cultivation requirements. At the same time, in the course of martial arts teaching content design, we should try to improve its novelty, and we should cross-present as many martial arts items as possible. For example, in the course of classroom teaching, we should mainly teach short routines and assist with attack, attack and defense technique, that will help to avoid the students feel very boring because of the single content of martial arts, and can improve the teaching quality and efficiency.

\section{Conclusion}

In a word, reforming the content of martial arts teaching in colleges and universities is an inevitable requirement for the development of education, and is also the only way to construct a new martial arts teaching system suitable for the needs of the times. In the course of reform of martial arts teaching content, all factors should be considered comprehensively, and the ideological preparation for a long war should also be made, because no reform can be accomplished overnight, and the reform of martial arts teaching content is no exception.

\section{References}

[1]ZHANG Yong. Reflections on the teaching reform of martial arts in colleges and universities[J]. Spiritual Leaders,2017(06).

[2]LUO Junbo. The enlightenment of "understanding teaching" to the reform of martial arts teaching in colleges and universities in China[J]. Education Modernization,2017(35).

[3]LI Hao. Research on the application of layered teaching method in martial arts teaching in colleges and universities[J]. Contemporary Sports Technology,2017(24).

[4]WANG Junfeng. Thoughts on martial arts culture education in martial arts teaching in colleges and universities[J]. Contemporary Sports Technology, 2016(04).

[5]MA Yiming. Reflections on the reform of martial arts teaching in colleges and universities in the new period[J]. Science \& Technology Information, 2017(11).

[6]LI Jiajing. Reflections on martial arts teaching in colleges and universities from the perspective of cultural inheritance[J]. Sport, 2017(09).

[7]YANG Qin, LV Wei, SU Qiguo. Research on the construction of multi-intelligence evaluation system of martial arts teaching in universities based on the cultivation of applied talents[J]. Technique of Practical Fighting, 2014(11).

[8]HAN Yubing. Reconstruction and leapfrogging of martial arts education in contemporary colleges and universities against the background of cultural development[J].Contemporary Sports Technology, 2015(21). 